\title{
Facing the challenges of the One-Tablet-Per-Child policy in Thai primary school education
}

\author{
Ratchada Viriyapong \\ Department of Mathematics \\ Naresuan University \\ Phitsanulok, Thailand
}

\author{
Antony Harfield \\ Dept. of Computer Science \& Information Technology \\ Naresuan University \\ Phitsanulok, Thailand
}

\begin{abstract}
The Ministry of Education in Thailand is currently distributing tablets to all first year primary (Prathom 1) school children across the country as part of the government's "One Tablet Per Child" (OTPC) project to improve education. Early indications suggest that there are many unexplored issues in designing and implementing tablet activities for such a large and varied group of students and so far there is a lack of evaluation on the effectiveness of the tablet activities. In this article, the authors propose four challenges for the improving Thailand's OTPC project, consisting of: developing contextualised content, ensuring usability, providing teacher support, and assessing learning outcomes. A case study on developing science activities for first year primary school children on the OTPC devices is the basis for presenting possible solutions to the four challenges. In presenting a solution to the challenge of providing teacher support, an architecture is described for collecting data from student interactions with the tablet in order to analysis the current progress of students while in a live classroom setting. From tests in three local Thai schools, the authors evaluate the case study from both student and teacher perspectives. In concluding the paper, a framework for guiding mobile learning innovation is utilised to review the qualities and shortcomings of the case study.
\end{abstract}

Keywords-educational technology; m-learning; mobile computing; tablet-based education

\section{INTRODUCTION}

Mobile devices have become more relevant in all aspects of everyday life, with a significant impact on education. Approximately $10 \%$ of the 650,000 apps available on the Apple App Store (and about 300,000 on the Android Market) are under the Education category and $72 \%$ of these are for preschool and elementary age children [1]. Reasons for the popularity of tablets for education include: (i) portability makes it more convenient to use in the classroom, (ii) overall cost of tablets is lower compared to the cost of computers, (iii) children like using touch-driven and highly interactive technology [2,3] and (iv) preschool children learn to use tablets quickly, independently, and confidently, showing freedom of exploration $[2,4]$.

As schools begin to accept the growing mobile culture, potential issues are being identified in the widespread adoption of mobile technology in the classroom. In the Bring Your Own Device (BYOD) schemes prominent in the U.S.A., devices can range from smartphones and tablets, to netbooks and laptops. According to a report by Tierney [5], one of the positive findings from BYOD projects is that instead of teachers controlling the learning process and knowledge, students have become "empowered learners and active proponents of their understanding and ability to connect ideas in new ways". However, the report also describes how BYOD can bring some difficulties to the school in practice, particularly in maintaining equality due to the different social/financial backgrounds and the wide range of devices available. Pilot projects found that the most common model, and the most successful, is for the school to define a single platform for BYOD [5]. Another wellknown large-scale project is the One Laptop Per Child (OLPC) scheme which has been supported by non-profit organizations to provide affordable educational devices for use in developing countries (over 2.5 millions devices shipped worldwide) [6]. Several large studies have been undertaken and some have shown that laptop use in school have only a little or no correlation with students' test scores [7] whereas in others the OLPC project was found to be effective in raising test scores [8]. An evaluation in Ethiopia reported that most teachers found trouble changing their teaching approach, which limited the use of the laptops in the class, whereas there was evidence in Haiti showing greater teacher engagement led to an enjoyable environment for students in the class [6]. Such studies indicate a wide range of high and low level issues for even the most successful widespread schemes like BYOD and OLPC.

Despite Thailand's status as a developing country, the current government's policy is radically in favour of adopting a tablet culture in schools. The government has given a tablet to every Prathom 1 (primary school, grade 1) child, loaded with approximately 336 learning objects (e-books, videos and interactive content) for five subjects including mathematics, science, Thai language, social studies and English language. To date, the project has delivered approximately 800,000 tablets to Prathom 1 students across Thailand - the biggest individual tablet procurement and the largest tablet experiment in the world. Their goal is for schoolchildren to "increase knowledge beyond textbooks", especially for those in remote areas who lack access to learning resources, as described by the Prime Minister, Ms. Shinawatra, during the official launch of the One-Tablet-Per-Child (OTPC) scheme on 7th June 2012 [9], Education minister, Mr. Suchart Tadathamrongvech, explained that some studies have shown the use of tablets is "a revolution in the education system", which will elevate the learning quality of Prathom 1 students at a fast-growing rate and could be another step of Thailand for upcoming integration into the ASEAN Community [10]. Within this scheme, the Office of the Basic Education Commission (OBEC) at the Ministry of 
Education is responsible for the installation of applications and content for all compulsory subjects. They also plan to train 549 supervisors to help instruct 54,900 Prathom 1 teachers in using tablets effectively (as yet, there is no information on the status of teacher training).

In comparison to the BYOD scheme, the OTPC project alleviates some of the problems of the BYOD project by using a single platform, single device model which eliminates the inconsistency of devices. Furthermore, the fact that they are given free to all students eliminates any social divisions. Compared to the OLPC project, tablets can provide advantages over laptop computers in terms of portability, cost, and efficiency (e.g. battery consumption and ease of recharging). Despite the practical advantages to tablets, there are still considerable challenges in realising an OTPC project as explored in this article.

\section{Challenges For OTPC}

The goals of the Thai government's OTPC project are ambitious and the future pedagogical challenges are even greater than the initial challenge of delivering 800,000 tablets to primary school children. This article specifically identifies four new challenges for the success of the OTPC project, as identified during early observations of school children using tablets and from discussions with primary school teachers using OTPC devices. While these new challenges are derived from experiences in Thailand, they are also deemed to be relevant to other large-scale mobile learning projects in schools.

\section{A. Contextualised content (challenge 1)}

Early OTPC observations have reported that due to a variation of educational competency in Thai schools (c.f. the rural versus city social divide), the tablet activities need to take into account the learning abilities in different regional areas across Thailand [11]. This may also include differences in culture and language that vary from region to region.

Hence content accessibility is a key requirement and special attention is needed in producing suitable content for different contexts. Teachers at local schools often complained that many students did not have adequate reading skills for the activities provided on the OTPC devices. Moreover, there can be a significant difference in literacy levels among schools within the same region, so the content would ideally be adaptable to the context of the individual child and their current ability.

While the tablet activities provided on the OTPC devices take a 'one size fits all' approach, the future challenge will be to provide learning content that is suitable for different regions, different social and cultural backgrounds, and different levels of literacy.

\section{B. Usability (challenge 2)}

A number of studies have reported that the usability of mobile technology can be a factor in the success of educational activities (e.g. see Corlett et al. [12]). Within the OTPC project, battery life, screen brightness and button defects have had negative impact, but these hardware issues are not considered in this study as they are factors outside the control of schools and teachers. Instead, consideration is given to the software issues, as they fall within the scope of improving the current OTPC project.

Teachers have reported that students can complete the entire body of activities in as little time as one month. This points to a flaw in that the tablet activities provide insufficient depth to the learner. In the same way that games such as Angry Birds (one of the bundled games included in OTPC) are providing a progression for the player, the learning activities should have a progression element to improve usability.

Another related issue is that the user interface in the OTPC affords a somewhat passive style of interaction whereby students 'watch and then click next'. Maintaining young children's attention requires interactive content that actively engages students. The design and implementation of such content can be time consuming, requiring significant testing and iterative development to ensure that usability is appropriate for primary school children.

\section{Teacher support (challenge 3)}

There have been widespread calls for better teacher training [13] that is vital to the success of OTPC. In many schools, the teachers do not have tablets, which are causing severe problems for class preparation. From observations by the authors, many teachers use the tablets as an alternative to teaching (e.g. one period per day the children undertake tablet activities) rather than as a complement to traditional classroom activities. Clearly there is a need to support the teacher in the classroom environment so that more blended learning experiences are possible. Aside from the need for teacher training, Van de Bogart [14] suggests that the solution is to design the tablet software for OTPC such that "teachers would become engaged as much as the pupils".

The challenge for providing better teacher support is intimately connected with how to provide better visibility to the teacher. In a traditional classroom, the teacher is directly aware of the students' interaction with the material. In a classroom with tablets, there needs to be similar support for the teacher by providing sensory information on the status of student's interaction with the tablet content.

\section{Learning outcomes (challenge 4)}

The final challenge, and perhaps the most difficult, is to address classroom management issues including evaluation of learning outcomes. One of the main concerns in a recent study of Thai primary school students using tablets in classrooms [15] was that "it is necessary for the teacher to monitor how students are using the tablet computer to achieve the learning objectives set out in the curricula".

If the focus is on assessing the learning outcomes of children using OTPC tablets, there is first a need for lesson plans that link the curriculum to specific tablet activities, so that a teacher has a basis for incorporating the use of tablets into their existing classes. Then, building on challenge 3, welldesigned tablet activities should have suitable data collection and analysis techniques, such that teachers and schools (as well as educators and technologists) can assess the learning outcomes of individuals, classes and schools. 

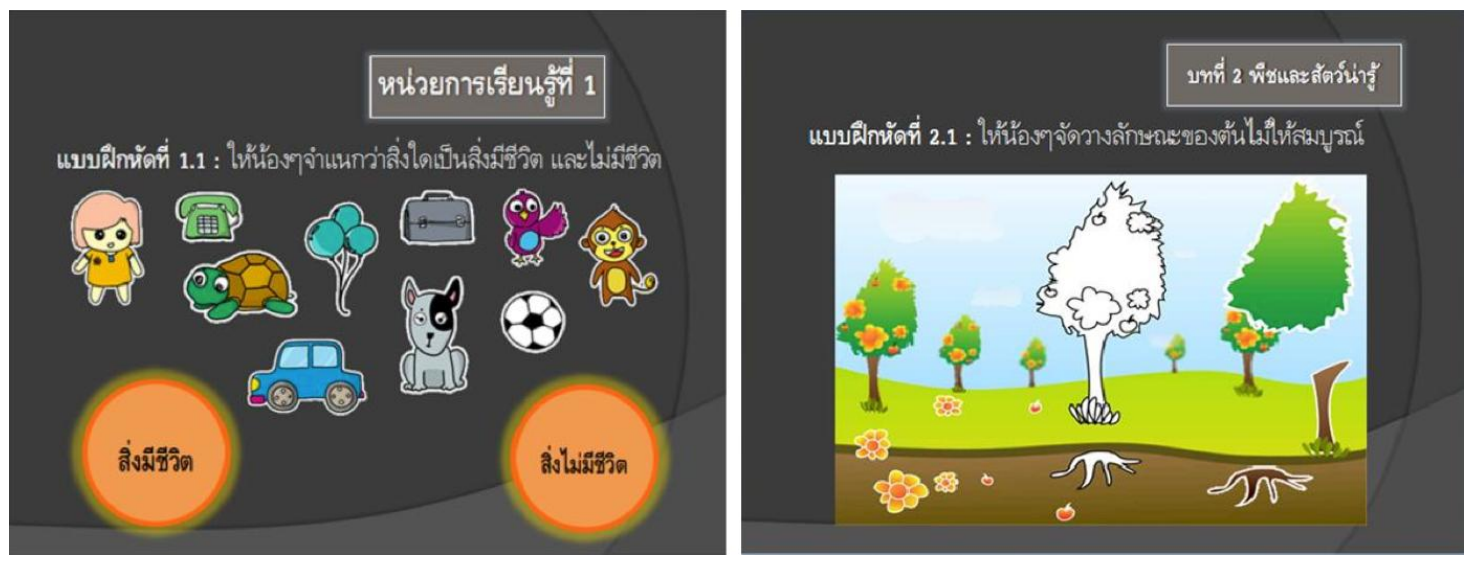

Fig. 1. Two of 50 activities designed for the first year science curriculum (on the left, for learning "things that have life", and on the right, for learning "parts of a tree/plant")

\section{Meeting The Challenges: A Case Study}

The "OTPC @ NU" research project began in 2012 with the aim of supporting local primary schools in Phitsanulok, Thailand, in obtaining greater benefit from the mobile devices provided by the OTPC project (see Mobile Computing Lab [16]). The project brief includes scope for developing and evaluating new tablet activities which are better suited to the needs of students, teachers and schools for primary school education in the local area of Phitsanulok (Prathom 1). The case study in this article focuses on how these new tablet activities provide some solutions to the challenges identified above, and where further work is still required.

\section{A. Method}

The current study follows the Lifecycle approach to evaluating educational technology, as described and applied by 17]. Unlike typical educational technology where evaluation is a particular phase of the project, the Lifecycle approach considers evaluation to play an important role in all stages of development, from the early stages of design through to implementation and testing.

Evaluation activities are undertaken at key stages in the lifecycle of the project, and inform the decisions in subsequent stages of the project. In this way, it shares common characteristics with the agile manifesto [18], which welcomes open evaluation and changes in requirements throughout the software development process. An agile approach was used during the software development process and hence, although the implementation is before and separate from the testing, the reality of the development process was that the preliminary testing contributed to further implementation cycles.

This case study is roughly described in three phases: (1) design of the learning activities, (2) implementation of the learning activities and related infrastructure, and (3) testing the learning activities and related infrastructure in live classroom environments. Teachers were involved in the evaluation of the design phase, and both students and teachers were involved in the evaluation of both implementation and testing phases. The evaluation was mostly informal and qualitative, but some quantitative was collected in the testing phase.

\section{B. Design}

In order to provide some background to the design process, it is useful to consider a typical OTPC classroom environment. The government currently has provided every first year primary school child with a 7 inch tablet running version 4.0 of Google's Android operating system. The tablets are pre-loaded with the OBEC's LSystem learning environment [9] that contains content for the entire first year Thai primary school curriculum (standardised across the country). Additionally, individual schools may choose to load extra applications or games. Individual schools set their tablet usage policies for how much time is spent with the tablets and what types of activities are expected. Typical usage involves a teacher and 10-20 students in a classroom, sat at desks formally performing tablet activities for up to an hour at a time.

The purpose of the case study was to develop a new set of activities for the science curriculum of first year primary students. At the initial stage of the design, consultation was sought from Thai teachers familiar with using tablets in schools. The first year curriculum for science was examined and topics suitable for tablet activities were selected. The science curriculum is broken down into 5 main topics, and 10 different learning activities were selected for each topic. Storyboards were created for the 50 activities. Examples of the storyboards are shown in Fig. 1. Primary school teachers evaluated the designs and after several rounds of iteration the activities were approved for a prototype implementation.

With consideration to the four challenges, the designed activities were directly based on content from textbooks used in several schools in the local area of Phitsanulok, thus partially attempting to satisfy the needs of challenge 1 in providing contextualised content. Furthermore, the activities were designed with typical lesson plans in mind due to the close relation to content in the textbooks. Thus each of the activities is linked to a learning outcome defined in the curriculum, providing support for challenge 4 . 


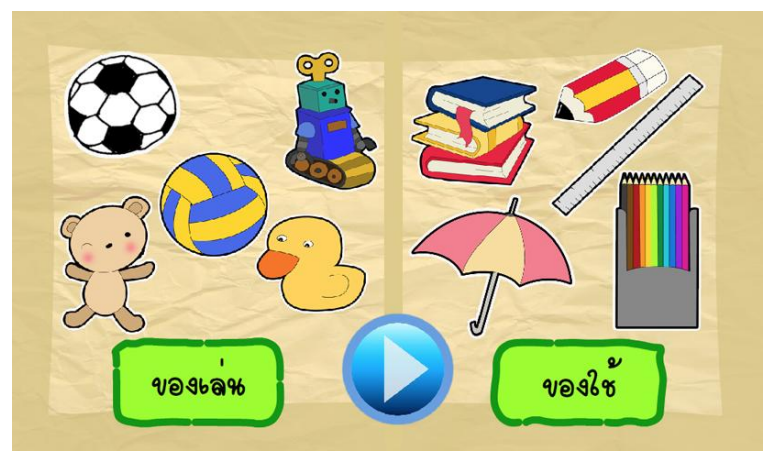

(a) Teaching phase (learning outcome)

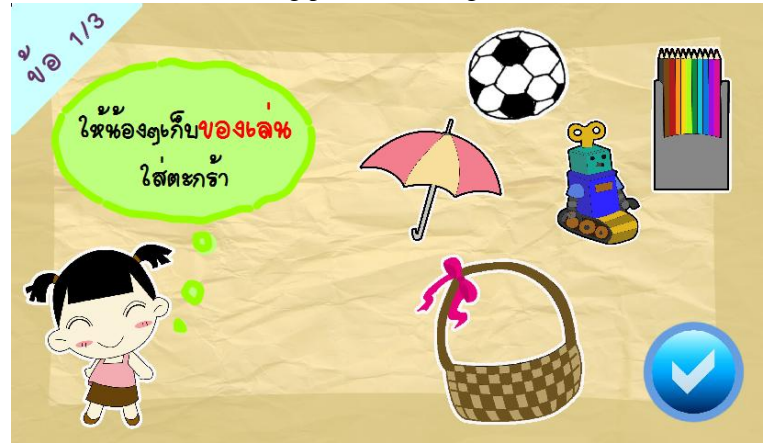

(c) Task phase (answer the questions)

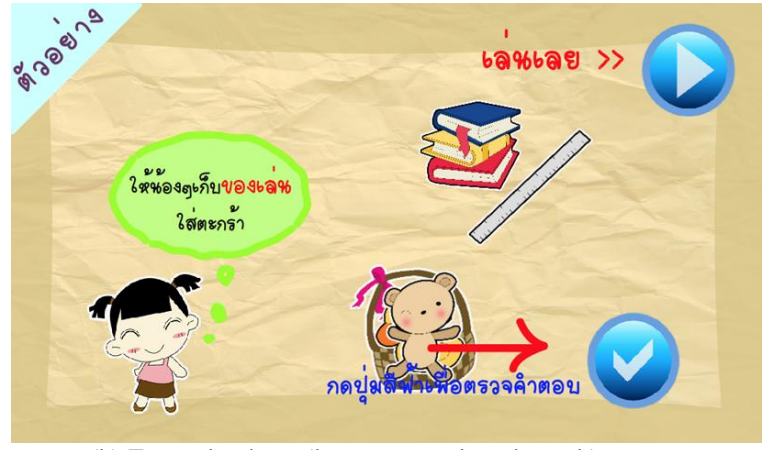

(b) Example phase (how to complete the task)

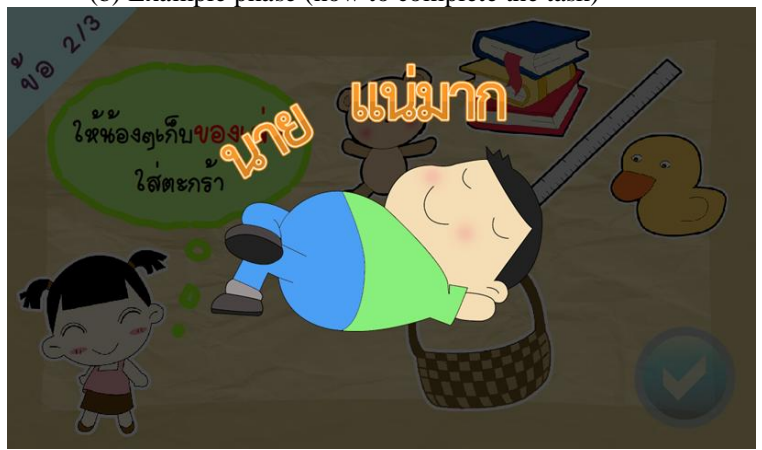

(d) Result (correct or incorrect feedback)

Fig. 2. The three phases for one activity and the result (topic: objects for work vs objects for play)

The new activities are designed to complement, not substitute, the Ministry of Education's science activities bundled with the OTPC devices. However, the purpose of this study is not to simply 'provide more content'. The four challenges identify issues with the current usage of the OTPC devices in schools, and therefore the main purpose of the study is to explore solutions to these somewhat broad issues by implementing new activities and testing them in a typical classroom environment.

\section{Implementation}

The activities were implemented using Adobe Flash CS5.5 with the programming in ActionScript 3.0, and deployed to Android tablets using AIR for Android [19] The AIR platform was selected because it is a similar approach to the standard first year activities provided by the Ministry of Education [9]. Out of the 50 storyboards, 44 were fully implemented (the remaining 6 were not completed due to technical difficulties). An example of one activity is shown in Fig. 2. Each of the activities consisted of 3 phases: teaching, example and exercise. In the teaching phase, the topic is introduced and the key piece of knowledge is explained to the student. In the example phase, the student is given an example of what they must do in the exercise. Finally the student will undertake the exercise, which might consist of multiple screens where they must perform a similar task. If they perform incorrectly then the task will be repeated, otherwise they can continue to the next activity. The activity in Fig. 2 first shows the teaching phase (a) explaining to the student that for the objects shown, some objects for play and some are for work. Next there is the example phase (b) showing how the student must select the objects for play and place them in the basket. Finally, the student will perform the task himself or herself (c) by dragging items into the appropriate basket and then the student will receive feedback (d) as to whether their answer was correct or incorrect.

Evaluation from testing early prototypes on school children played a significant role in ensuring that the usability (challenge 2) was suitable for the target group. Furthermore, the testing was essential for adding depth to the activities such that students could return to the activities to replay or progress further into the activities, as highlighted as part of challenge 2 .

Challenge 3 was partially addressed during the implementation by developing a logging system for collecting data that would enable the teacher to view the progress made by each student. To accomplish this, it was necessary to send precise data on the interaction between student and tablet to a central server. A simplistic solution to this would be to send the data in real-time to the server. However, in a rural school environment (even more so in a home environment) there is no guarantee that a permanent wireless network is available, or that an Internet connection is present. Hence the need for an "offline" solution to data collection.

The architecture for collecting data from the tablet activities is shown in Fig. 3. The solution involves sending the logging data from the Flash activity to a background Android service that stores it in a local database. The service periodically polls the network to check if a connection to the cloud-based server can be made. When the connection is available, the data from the local database is forwarded to the server and removed from the local database. The data from multiple devices (from multiple sessions) is stored on the cloud-based server ready for analysis. A detailed description of the architecture is given by Nakrang et al. [20]. 


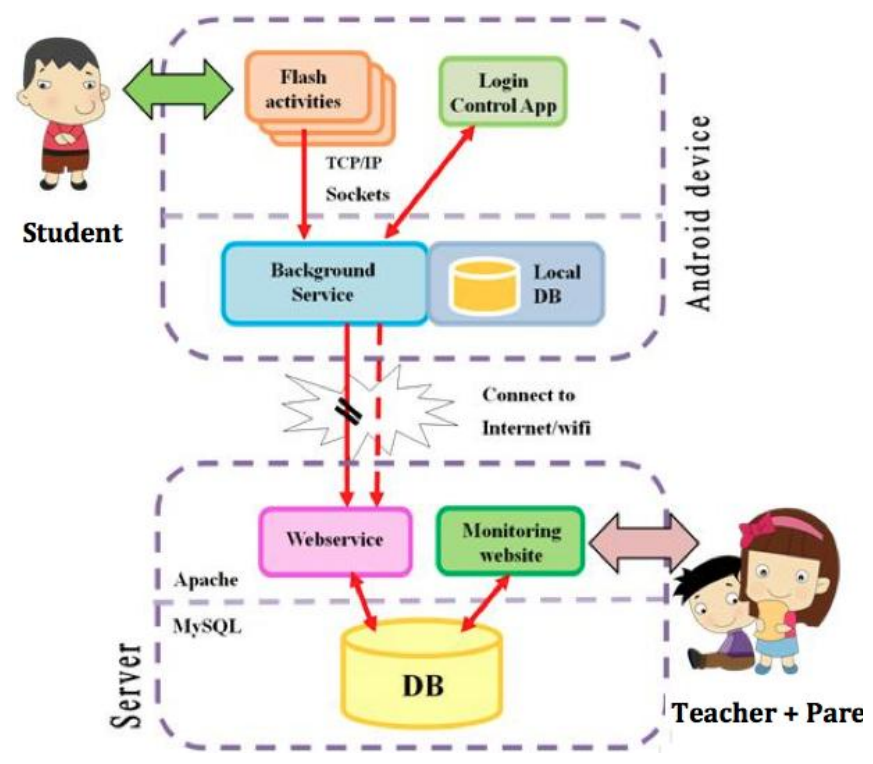

Fig. 3. The overall architecture for tablet activities and data collection

The data collected is valuable on two levels, corresponding directly to the two issues set out in challenges 3 and 4 . Firstly, assuming the classroom has provision for the data to be collected in real-time (via a wireless Internet connection), then the teacher has a live source of information for understanding the current progress of every student in the classroom. The information can be made available to the teacher via a website viewable on a laptop or tablet (bottom-right of Fig. 3).

A prototype for possible visualisation of the data is shown in Fig. 4, consisting of test data from four student groups. The metrics displayed to the teacher include the last 12 interactions of the four groups, the total number of activities completed and the number of failures that have occurred. In the current progress of the class in Fig. 4, group 2 has yet to complete any activities which are one simple observation that would interest a teacher. Another observation would be that group 1 is producing incorrect answers to a large number of activities. Such insights could prompt the teacher to engage with certain students and goes some way to provide support for the teacher in terms of challenge 3. Teacher evaluation of this part of the system has been particularly positive, but further work is needed to understand the precise needs of the teacher.

The second valuable contribution of the collected data is in assessing the learning outcomes as per challenge 4 . At the end of class, the teacher can view the individual progress of each student or the class as a whole. A teacher might be interested in which activities the students had difficulties with in order to plan extra offline work or future lessons. Aside from the teacher, the school as a whole might be interested in comparing learning outcomes between classes and parents might be interested in comparing their child with others in the class. The possible uses of the data for evaluation are broad and as yet unexplored by the authors. Further analysis on the potential for evaluating learning outcomes for challenge 4 is discussed in the following section.

\section{Testing}

Tests were performed on two occasions. The "preliminary tests" were undertaken in May 2012 at two schools in Amphur Bang Krathum, Phitsanulok. Following the feedback from the preliminary tests, the activities were revised and the software updated. The "final tests" were undertaken in September 2012 on a different group of students at one school in Amphur Muang, Phitsanulok.

The first of the preliminary tests was at a small local village school called Hnong Sra Phang School. We tested the activities on Prathom 1 and Prathom 2 students, approximately 12 students. We tested the students individually with a set of chosen activities for 20 minutes each. A researcher observed the student at all times, and provided guidance when difficulties occurred. The second was at a larger school called Wat Dong Hmee School where there were 20 Prathom 1 students. During this test, the students worked in groups of 2-3 per tablet, overseen by a researcher. They undertook the same activities for a 20 minute period. At least one teacher was onhand during the tests and their feedback also contributed to the evaluation.

The final tests were undertaken at Wat Kung Waree School where there are 20 Prathom 1 students. They were split into groups of 2-3. The boys and the girls were tested independently, the first set of groups (1-4) consisted of all boys, and the second sets of groups (5-6) were all girls. Each group undertook a set of activities for 30 minutes. In the final tests, we collected detailed usage data from each tablet, including: (1) the number of activities played, (2) the amount of time spent on each activity, and (3) for each activity, the number of tasks that were passed and failed. The data was recorded via the architecture presented in Fig. 3. Some videos were also recorded for subsequent analysis. Due to the young age of the participants (Prathom 1 school children) it was not deemed appropriate to use questionnaires or interviews.

The evidence gathered from the preliminary tests was purely qualitative, and provided the evaluation that contributed to the iterative development of the activities. As discussed below, the preliminary tests provided essential feedback in overcoming challenges 1 and 2 . The final tests provided some qualitative evidence verifying the improvements made over the preliminary tests, but they also focussed more on teacher support by gathering qualitative data that could be used as a basis for approaching challenges 3 and 4 .

\section{Results And Discussion}

Of the four challenges for OTPC identified in this work, the first two can be considered as focusing more on supporting the student, whereas the last two focus more on supporting the teacher.

\section{A. Contextualised content and usability (student-focussed)}

Despite consultation from teachers during the design and implementation, the observation of students in the preliminary tests highlighted a number of problems as detailed in Table 1. The majority of these problems could be categorised as usability issues (challenge 2) or content issues (challenge 1). To overcome the issues it was necessary to redesign some areas 


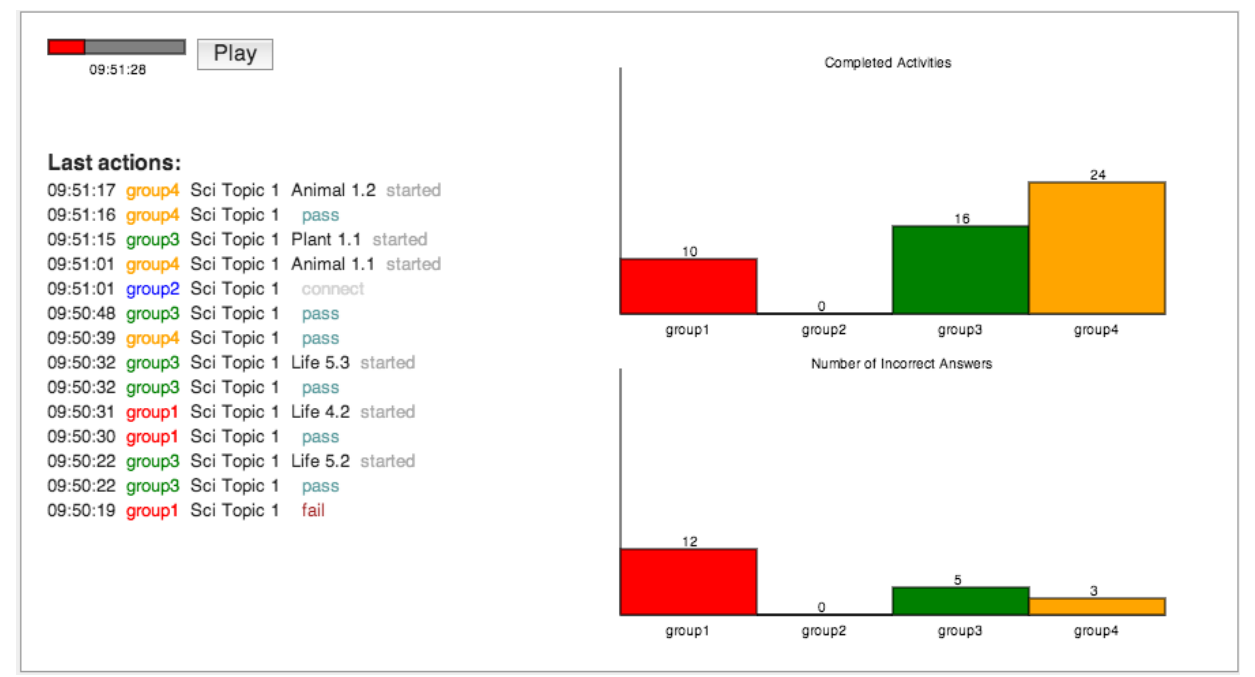

Fig. 4. Sample of the live monitoring website for teachers

of the user interface and to provide better support for students of different literacy levels (e.g. removing text and adding icons and voice-over).

TABLE I. OBSERVATIONS From THE PRELIMINARY TESTS

\begin{tabular}{|c|c|c|}
\hline Observation & Problem & Solution \\
\hline $\begin{array}{l}\text { Students often do } \\
\text { not know which } \\
\text { parts of the } \\
\text { screen to press. }\end{array}$ & $\begin{array}{l}\text { The buttons are not clear } \\
\text { enough and they are } \\
\text { inconsistently used } \\
\text { (challenge 2, badly } \\
\text { designed interface). }\end{array}$ & $\begin{array}{l}\text { Use one style of } \\
\text { button throughout } \\
\text { the activities. Use } \\
\text { highlighting/anim } \\
\text { ation to indicate } \\
\text { that the button can } \\
\text { be pressed. }\end{array}$ \\
\hline $\begin{array}{l}\text { Some students } \\
\text { are not familiar } \\
\text { with dragging } \\
\text { objects on a } \\
\text { touchscreen. }\end{array}$ & $\begin{array}{l}\text { There is no training for } \\
\text { the students on how to } \\
\text { drag, or what can be } \\
\text { dragged (challenge 2, } \\
\text { unfamiliar user } \\
\text { interface). }\end{array}$ & $\begin{array}{l}\text { Animation can be } \\
\text { added to show an } \\
\text { example of how } \\
\text { to drag. A tutorial } \\
\text { page would also } \\
\text { be useful. }\end{array}$ \\
\hline $\begin{array}{c}\text { Many Prathom } 1 \\
\text { students cannot } \\
\text { read }\end{array}$ & $\begin{array}{l}\text { These students cannot } \\
\text { read the text from the } \\
\text { activities and therefore } \\
\text { cannot do the activities } \\
\text { without support } \\
\text { (challenge 1, different } \\
\text { levels of reading skills). }\end{array}$ & $\begin{array}{l}\text { Provide voice- } \\
\text { over on all } \\
\text { activities so that } \\
\text { reading is not } \\
\text { required. }\end{array}$ \\
\hline $\begin{array}{l}\text { Some activities } \\
\text { were too difficult } \\
\text { and required } \\
\text { teacher support/ } \\
\text { explanation. }\end{array}$ & $\begin{array}{l}\text { Activities require } \\
\text { explanation before the } \\
\text { task begins (challenge } 1 \\
\text { or } 2 \text {, inappropriate } \\
\text { content or badly } \\
\text { designed interface) }\end{array}$ & $\begin{array}{l}\text { Before the task, } \\
\text { add a teaching } \\
\text { page and an } \\
\text { example page to } \\
\text { show the what } \\
\text { and how. }\end{array}$ \\
\hline
\end{tabular}

After improving the activities from preliminary results, in the final tests the students required much less support in using the activities. Several groups were able to use the activities independently for more than 10 minutes without support from the teacher. High levels of attention and engagement were observed. For example, in one video recorded there is evidence that the two boys were focussed on solving the task set in the activity. They each took it in turns to make an attempt, the other offering advice at the same time. After one of the boys got it incorrect the other showed clear signs of amusement and pleasure that it was his turn to show his friend. This was then repeated the other way around until eventually one of the boys solved the activity. These results are purely speculative as there may be other explanations, e.g. the students in the final tests were more familiar with computers or mobile technology.

One obvious result is that the activities in final tests were more successful because the preliminary tests helped to resolve many interaction difficulties that the previous group of students had experienced. Whereas the difficulties in the preliminary tests were technical in nature, in the final tests the difficulties were more pedagogical or organisational. The following issues were observed:

- When in small groups, the students often tended to argue to be in control, or one student would take control. This would not be a problem if they each had their own tablet.

- Although the activities in the final tests contained voiceover to improve accessibility, a few of the activities still required some reading ability, and this was a problem for some students.

- Occasionally the students would not listen at the right time to get the voice-over instructions, and then they would not know how to solve the task. This could be solved by implementing an idle sensor and repeating the instructions if necessary, or by adding a repeat button.

These observations demonstrate that activities can be continually improved in terms of contextualised content and usability. The eventual outcome of the case study has been that a number of local schools have requested the set of science activities and, following final improvements to content and usability, we plan to roll-out the activities to ten schools in May 2013.

\section{B. Teacher support and learning outcomes (teacher-focussed)}

In contrast to the challenges of supporting the student with content that is contextualised and usable, the challenges of supporting the teacher with visibility of student progress and learning outcomes require a different style of evaluation. 


\begin{tabular}{|c|c|c|c|c|c|c|c|c|c|c|c|c|}
\hline 4 & \multicolumn{2}{|l|}{ A } & \multicolumn{2}{|l|}{ B } & \multicolumn{2}{|c|}{ C } & \multicolumn{2}{|l|}{ D } & \multicolumn{2}{|l|}{$E$} & \multicolumn{2}{|l|}{$\mathrm{F}$} \\
\hline 1 & ActivityDate & - & ActivityType & - & AppId & $\nabla$ & UserId & $\because \mathrm{s}$ & SessionId & & ActivityData & $\nabla$ \\
\hline 2 & $2012-09-25$ 09:41:51.391 & & connect & & Sci Topic 1 & & group1 & $\hat{z}$ & Sort $A$ to $Z$ & & & \\
\hline 3 & $2012-09-25$ 09:42:48.272 & & started & & Sci Topic 1 & & group1 & $\mathrm{z} \downarrow$ & Sort $Z$ to $A$ & & & \\
\hline 4 & $2012-09-25$ 09:43:20.592 & & pass & & Sci Topic 1 & & group1 & & Sorț by Color & & , & \\
\hline 5 & $2012-09-25$ 09:43:20.904 & & started & & Sci Topic 1 & & group1 & 6 & Clear Filter From ? & serild & & \\
\hline 6 & $2012-09-25$ 09:43:42.486 & & pass & & Sci Topic 1 & & group1 & k & Filter by color. & & , & \\
\hline 7 & $2012-09-25$ 09:43:42.801 & & started & & Sci Topic 1 & & group1 & & Filter by color & & 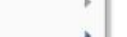 & \\
\hline 8 & $2012-09-25$ 09:44:01.900 & & pass & & Sci Topic 1 & & group1 & & Text Eilters & & ? & \\
\hline 9 & $2012-09-25$ 09:44:30.064 & & started & & Sci Topic 1 & & group1 & & $\checkmark$ (Select All) & & & \\
\hline 10 & $2012-09-25 \quad 09: 44: 43.838$ & & fail & & Sci Topic 1 & & group1 & & group1 & & & \\
\hline
\end{tabular}

Fig. 5. Raw data collected from tablets in the final tests

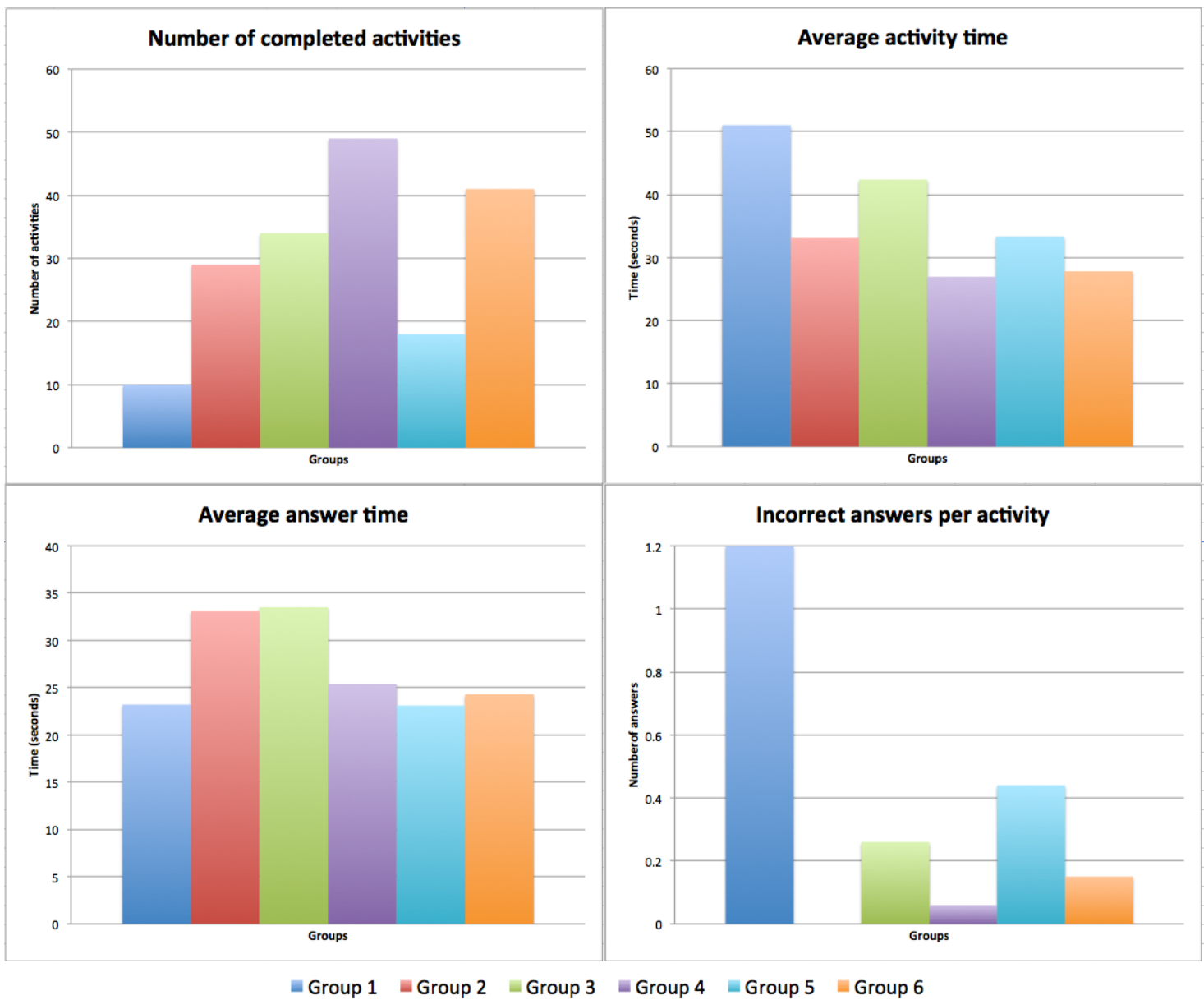

Fig. 6. Data of all six groups of students: (top-left) total number of completed activities per group, (top-right) average time spent to complete each activity (seconds), (bottom-left) average time spends to answer one task (seconds) and (bottom-right) failure rate in each activity (number of incorrect answers per activity).

During the final tests, data on every interaction between student and tablet was collected in real-time on the tablet and sent to the server. The claim to be explored in this section is that the collected data is valuable for supporting the teacher in understanding the progress of the students and the learning outcomes of the class. In order to explore the potential support for the teacher in more detail, the data set was exported for analysis in the form of a spreadsheet as shown in Fig. 5. The data consists of: (A) date and time of the event, (B) the type of event (e.g. "started" activity, "pass" / "fail" activity), (C) the activity topic, $(\mathrm{D}, \mathrm{E})$ the user identity, and $(\mathrm{F})$ the activity name.
From simple data analysis, a number of features can be visually extracted through plots and graphs, for example: (i) the total number of activities completed by each student, (ii) the number of correct or incorrect answers given by each student, (iii) the total time spent in each activity; (iv) the average time between the start of an activity and the student giving a correct or incorrect answer (called the "answer time"). The average answer time is different from the total activity time because each activity has multiple tasks (as described in the implementation), and if a task is answered incorrectly then the student must try again. Therefore the average answer time is a 
measure of how quickly the student enters an answer irrespective of whether it is correct or not.

As shown previously in Fig. 4, the aim of collecting data is to support the teacher in monitoring the live progress of their class. However, the purpose of extracting the data for further analysis as a one-off exercise is to explore potential solutions to challenges 3 and 4 . The eventual goal is to make this extended analysis available to teachers in real-time through a website as in Fig. 4.

The four graphs plotted in Fig. 6 show the data collected from six groups of students at Wat Kung Waree School over a period lasting 30 minutes. The number of activities they completed within the time provided was different depending on their ability, concentration and behaviour. On average there were 30 activities completed by each group and the average time spent in each activity was 33 seconds. From the top-left graph, group 4 completed the most activities, and group 1 completed the fewest. As might be expected, group 1 spent a considerably longer period of time completing activities, with group 4 spending the least time per activity.

According to Fig. 6 top-right, groups 1 and 3 spent more time to complete each activity than the rest of students whereas group 4 spent the least time to complete each activity. An initial analysis of this might conclude that group 4 was the best among all six groups. However, further investigation into the students' average answering time (defined as the time from starting the task to pressing 'submit') and the number of failures made by each group was performed as shown in Fig. 6 (bottom-left and bottom-right). From the graph in the bottomright, group 1 had the worst failure rate (1.2 fails/activity) among others, whilst group 2 had a zero failure rate (they passed all activities on their first attempt). Failure rate of students in group 5 was also high compared to the rest of the groups. The high rate of failure in group 1 and 5 is valuable information to the teacher who cannot observe all of the students at once in order to tell who is failing. Is the reason for failure because the students' knowledge and understanding of the subject is insufficient? Or were the students over-zealous when they did the activity without any intention to think through the task? Hence the considerations of the students' average answer time, bottom-left graph. Interestingly, the graph shows that both group 1 and 5 spent the least time thinking before they submitted their answer in each activity at 23.2 and 23.1 seconds, respectively. On the other hand, students in group 2 spent 33.1 seconds before they submitted each activity.

Hence, according to the data obtained, we could divide the groups of students into three categories; (i) students who quickly submitted their work/activity and had a high rate of failure - they were group 1 and 5, (ii) students who gently and carefully did their work before they submitted, leading to no or little failure rate - they are group 2 and (iii) students who quickly submitted their work but had so little failure rate still they are group 4. Among all the groups, this analysis shows that group 4 was the most efficient in terms of time spent and failures. The group that needs most support from the teacher would be group 1 .

The failure rate and thinking time might be suitable metrics for analysing overall student behaviour, but the teacher is likely to also be interested in which activities or topics that the class as a whole found difficult, as it relates to assessing the learning outcomes (challenge 4). Some further analysis was carried out on the data and found that most students had a problem doing exercise named "Life 2.1". Within this activity, students in group 1 failed three times and group 4 failed one time, whereas students in group 2 and 3 spent 42 and 34 seconds, respectively in completing the activity correctly which was rather long time spent comparing to other's activity time spent. This problem could be because the content relating to Life 2.1 activity was more difficult than others, which would prompt the teacher to consider giving further explanation or examples on the topic. Such insights would enable the teacher to assess the learning outcomes in ways that are not currently possible with the regular OTPC activities. At an even higher level, it could be claimed that the data is valuable for analysing the performance across an entire school, in terms of comparing class achievement and assessing whether achievement matches expectations based on the curriculum. Each of these claims require individual investigation, the observation here is that the current study offers a solution to providing relevant data to the teacher to inform their own decision on the progress of individual students or the entire classroom.

\section{CONCLUSION}

Within the relatively recent field of mobile learning, prominent scholars Vavoula \& Sharples [21] have proposed a framework for evaluating mobile learning 'M3' which includes five precepts for guiding the development of mobile learning innovation. In concluding this article, it is relevant to consider the case study in light of these five precepts in order to reflect on the contribution to a wider mobile learning community. The qualities and shortcomings of the case study in terms of the five precepts are reviewed in Table 2 . It shows the reality of the work that still needs to be done to better understand the needs of the OTPC project.

Although BYOD and OLPC schemes are leading largescale mobile technology facilitation in schools with support nationally and internationally, Thailand's OTPC project is an equally impressive experiment that merits interest from the mobile learning community. While the Thai Ministry of Education focuses on the logistics of distributing and maintaining 800,000 tablets, there is much work needed on addressing the pedagogical challenges. This article highlights, and provides some solutions to, only four challenges that are deemed relevant to current OTPC issues in Thailand. The challenges address issues on both the side of the learner, in providing deeper more engaging learning experiences to the primary school child, and the side of the teacher, in providing relevant support in a classroom environment to assess progress and learning outcomes. Considered in light of the five precepts for mobile learning innovation (as shown in Table 2), considerable work is needed on a much wider range of issues if the impact of OTPC on primary school education is to be better understood. The need is urgent, as the Ministry of Education is preparing a larger roll-out to second year primary school children beginning October 2013. Time will tell whether the OTPC project can have a lasting effect on improving educational in Thailand - certainly it promises to be an exciting opportunity for mobile learning research. 
TABLE II. THE FIVE PRECEPTS For GUIDING MoBILE LEARNING INNOVATION, TOGETHER WITH SUGGESTED QUALITITIES AND SHORTCOMINGS OF THE CURRENT CASE STUDY

\begin{tabular}{|c|c|}
\hline Precept & Case study qualities/shortcomings \\
\hline $\begin{array}{l}\text { P1. Capture and analyse } \\
\text { learning in context, with } \\
\text { consideration of learner } \\
\text { privacy }\end{array}$ & $\begin{array}{l}\text { New activities successfully tested in the } \\
\text { classroom context, and data } \\
\text { captured/analysed from the perspective of } \\
\text { the teacher } \\
\text { No consideration given to learner privacy }\end{array}$ \\
\hline $\begin{array}{l}\text { P2. Assess the usability } \\
\text { of the technology and } \\
\text { how it affects the } \\
\text { learning experience }\end{array}$ & $\begin{array}{l}\text { Multiple tests in schools showed } \\
\text { improvements in usability } \\
\text { Later tests demonstrated increasingly } \\
\text { independent learning, but difficult to qualify } \\
\text { the improvement }\end{array}$ \\
\hline $\begin{array}{l}\text { P3. Look beyond } \\
\text { measurable cognitive } \\
\text { gains into changes in the } \\
\text { learning process and } \\
\text { practice }\end{array}$ & $\begin{array}{l}\text { Not yet well addressed, but clear that the } \\
\text { tablets can change the learning process with } \\
\text { both positive and negative (c.f. increased } \\
\text { enthusiasm for technology in the classroom } \\
\text { vs. decreased student-to-student interaction) }\end{array}$ \\
\hline $\begin{array}{l}\text { P4. Consider } \\
\text { organisational issues in } \\
\text { the adoption of mobile } \\
\text { learning practice and its } \\
\text { integration with existing } \\
\text { practices and understand } \\
\text { how this integration } \\
\text { affects attributes of } \\
\text { in/formality }\end{array}$ & $\begin{array}{l}\text { Case study proposes solutions to the } \\
\text { challenge of teacher support within a formal } \\
\text { classroom environment } \\
\text { Hardware and infrastructure issues not yet } \\
\text { considered (c.f. effects of usability on } \\
\text { classroom management addressed by Lim } \\
{[22] \text { ) }}\end{array}$ \\
\hline $\begin{array}{l}\text { P5. Span the lifecycle } \\
\text { of the mobile learning } \\
\text { innovation that is } \\
\text { evaluated, from } \\
\text { conception to full } \\
\text { deployment and beyond }\end{array}$ & $\begin{array}{l}\text { Case study involved teacher/student input } \\
\text { from conception through to final deployment } \\
\text { No opportunity yet to compare the new } \\
\text { activities with the old activities over a longer } \\
\text { period of time - possible future work }\end{array}$ \\
\hline
\end{tabular}

\section{ACKNOWLEDGMENT}

The authors would first like to thank the three schools that allowed us to undertake the testing and evaluation as well as the many teachers who gave us feedback on the design and content of the activities. Two talented final year undergraduates in computer science, Jenjira Nakrang and Donnapa Yata, developed the storyboards, activities and software. Further thanks go to Me\&Friends Studio in Chiang Mai for their guidance throughout the design and implementation.

\section{REFERENCES}

[1] C. Shuler, "iLearnII: An Analysis of the Education Category of the iTunes App Store", New York, NY: The Joan Ganz Cooney Center at Sesame Workshop, 2012.

[2] M. Cohen, "Young Children, Apps \& iPad", Research report prepared for U.S. Department of Education Ready to Learn program, 2011. URL: http://mcgrc.com/wp-content/uploads/2012/06/ipad-study-cover-pagereport-mcg-info_new-online.pdf

[3] C. Shuler, "Pockets of potential: Using mobile technologies to promote children's learning", New York, NY: The Joan Ganz Cooney Center at Sesame Workshop, 2009.
[4] L.J. Couse \& D.W. Chen, "A tablet computer for young children? Exploring its viability for early childhood education" Journal of Research on Technology in Education, 43(1), 75-98.

[5] S. Tierney, "Bring Your Own Device to school", report by Microsoft Corporation, 2012.

[6] D. Nugroho \& M. Lonsdale, "Evaluation of OLPC programs globally: a literature review (Version 4)", Australian Council for Educational Research, 2010.

[7] M. Warschauer, "Laptops and Literacy: A Multi-Site Case Study", Pedagogies: An International Journal, 3, 52-67, 2008.

[8] L.L. Linden, "Complement or Substitute? The effect of Technology on Student Achievement in India", Poverty Action Lab, 2008. URL: http://www.povertyactionlab.org/publication/complement-substituteeffect-technology-student-achievement-india

[9] L. Intathep, "One Tablet PC Per Child scheme launch at Government house", 7th June 2012. Bangkok Post. URL: http://www.bangkokpost.com/news/local/297070/yingluck-wants-tabletuse-tracked

[10] National News Bureau of Thailand, "OBEC demonstrates use of tablet PCs for Prathom 1 students", April $4^{\text {th }}$ 2012. URL: http://202.47.224.92/en/news.php?id=255504040013

[11] L. Intathep, "Tablet study finds city, rural schools need different content", 21st February 2012, Bangkok Post. URL: http://www.bangkokpost.com/news/local/280760/tablet-study-finds-cityrural-schools-need-different-content

[12] D. Corlett, M. Sharples, S. Bull \& T. Chan, "Evaluation of a mobile learning organiser for university students", Journal of Computer Assisted Learning, 21: 162-170, 2005.

[13] C. Saengpassa \& W. Khaopa, "The Fun They Had: Government urged to train teachers on use of computer tablets to enhance pupils' learning", $13^{\text {th }}$ February 2012, The Nation. URL: http://www.nationmultimedia.com/national/The-fun-they-had30175709.html

[14] W. Van De Bogart, "Child Development Issues Related to Thailand'sTablet Computer Policy within the ASEAN Community", Proceedings of ASEAN Scenario Analysis 2015-2020 Conference, Bangkok University, May 25, 2012.

[15] W. Van de Bogart, "Developing Multi-literacy Skills in e-Learning Environment using Tablet Computers at the Primary Grade Level in Thailand". Proceedings of The Fourth TCU International e-Learning Conference Smart Innovations in Education \& Lifelong Learning, Muang Thong Thani, Thailand. June 14-15, 2012.

[16] Mobile Computing Lab. The One-Tablet-Per-Child @ NU project kicks off. April 2003. URL: http://www.mobcomlab.com/?p=129

[17] G. Vavoula, J. Meek, M. Sharples, P. Lonsdale \& P. Rudman, “A Lifecycle approach to evaluating MyArtSpace". Proceedings of 4th IEEE International Workshop on Wireless, Mobile and Ubiquitous Technology in Education, WMUTE '06. November 16-17, 2006. pp.1822.

[18] K. Beck, et al. "Manifesto for Agile Software Development". Agile Alliance, 2002. URL: http://agilemanifesto.org/

[19] V. Brossier, "Developing Android Applications with Adobe AIR", O'Reilly Media Inc, 2012.

[20] J. Nakrang, D. Yata, \& A. Harfield, "Interactive tablet activities for science education in Thai primary schools", Proceedings of 1st ASEAN Undergraduate Conference in Computing (AUCC), Chantaburi, Thailand, February 14-15, 2013.

[21] G. Vavoula \& M. Sharples, "Meeting the challenges in evaluating mobile learning: a 3-level evaluation framework", International Journal of Mobile and Blended Learning, 1(2), pp. 54-75, 2009.

[22] C.P. Lim, Y.H. Teo, P. Wong, M.S. Khine, C.S. Chai \& S. Divaharan, "Creating a Conducive Learning Environment for the Effective Integration of ICT: Classroom Management Issues", Journal of Interactive Learning Research, 14(4), 405-423. Norfolk, VA: AACE, 2003. 